\title{
Identification of CF Mutations and Clinical Symptoms in CBAVD Patients
}

\author{
M Mafruchati ${ }^{1, *}$, Jonathan Makuwira ${ }^{2}$
}

\section{Mafruchati ${ }^{1, *}$, Jonathan Makuwira $^{2}$}

'Department of Veterinary Anatomy, Faculty of Veterinary Medicine (60115), Universitas Airlangga, Mulyorejo, C Campus, Surabaya, INDONESIA.

${ }^{2}$ Malawi University of Science and Technology, P.O Box 5196, Limbe, Malawi.

\section{Correspondence}

\section{Mafruchat}

Department of Veterinary Anatomy, Faculty of Veterinary Medicine (60115), Universitas Airlangga, Mulyorejo, C Campus, Surabaya, INDONESIA.

E-mail: maslichah-m@fkh.unair.ac.id

History

- Submission Date: 28-08-2021.

- Review completed: 04-10-2021;

- Accepted Date: 04-01-2022.

DOI : 10.5530/pj.2022.14.14

Article Available online http://www.phcogj.com/v14/i1

\section{Copyright}

(C) 2022 Phcogj.Com. This is an openaccess article distributed under the terms of the Creative Commons Attribution 4.0 International license.

\begin{abstract}
CBAVD has a prevalence or morbidity rate of 1-2 percent and has an association with low sperm count and damage, including being associated with recessive inherited genetic disorders. In 1971, several men with CBAVD were identified and had an association with mild cystic fibrosis. The classic clinical symptoms of cystic fibrosis are chronic diseases of the lungs, exocrine disorders of the pancreas, increased electrolyte levels in the sweat glands. It is based on various studies that the mutation frequency in CFTR is very high in patients with CBAVD compared to non-CBAVD patients. The $5 \mathrm{~T}$ allele on intron 8 causes changes in amino acids that is elevated when there is translation in the mRNA. The $5 \mathrm{~T}$ variant is a common mutation associated with the CBAVD phenotype and clinical symptoms. The method used in writing this review article is online literature studies obtained by accessing national and international scientific journals as well as scientific articles related to CF mutation and clinical symptoms. From the results of research that has been done, mutations in CBAVD patients have differences in clinical symptoms and require further study, especially with regard to the immunological expression profile in patients using animal models.

Key words: Mutations, Clinical symptoms, CBAVD, Infectious Disease.
\end{abstract}

\section{INTRODUCTION}

CBAVD has an incidence of 1-2 percent in men who experience infertility, followed by damage to the Wolffian duct or ducts that taper to the vas deferens, epidymis, seminal vesicles and ejaculatory ducts. CBAVD is caused by a lack of sperm count due to a natural defect caused by an autosomal recessive genetic disorder. This is sometimes referred to as an infectious disease.

It is known that in 1971, several men with CBAVD and cystic fibrosis were identified and associated with the CFTR gene. Based on several studies, the CFTR gene has a relationship with CBAVD and is genetically associated with cystic fibrosis, the clinical symptoms that are often found are chronic lung disease, exocrine disorders of the pancreas, increased electrolyte levels, male infertility with an incidence of more than $95 \%$ and causes reduced sperm count. ${ }^{1-5}$

Various studies show that there is a very high change in allele, especially people with CBAVD. intron no. 5 in allele no. 8 is more dominant than exon 9 which has decreased transcription than with two alleles 7T and 9T. Variant $5 \mathrm{~T}$ mutates more frequently in CBAVD, although it shows less clinical symptoms. This is due to heterogeneity in CBAVD and differences in spectrum in mutated CFTR genes compared with patients with cystic fibrosis, so far this has not been reported. there is insufficient data on CBAVD molecularly. ${ }^{6-10}$

This is associated with high levels of ethnic heterogeneity and geographic differences, mutations in cystic fibrosis are more common in IVS8 polymorphisms in CBAVD patients and clinical symptoms that appear have a relationship or correlation with CBAVD genotypes and cystic fibrosis as well as in patients with CBAVD who experience infertility and deficiency. the number of sperm that is obstructive. Men with CBAVD are at higher risk of cystic fibrosis and their partners are carriers of the cystic fibrosis mutation ${ }^{10}$ the purpose of this research was to analysis CBAVD patients and their clinical symptoms.

\section{METHOD}

$5 \mathrm{ml}$ of whole blood, prepared and taken from each patient's PBMC, accompanied by clinical symptoms and patient medical records. Samples of CF patients were carried out to determine mutations based on alleles using PCR. Reagents, concentrations, primers and PCR cycles following the procedures of Araoujo, et al 2005 and Lago, et al 2017.

\section{RESULTS AND DISCUSSION}

Based on the study, seven eight percent of patients with CBAVD will carry more than change, fortyeight percent are simultaneous, the majority of mutations in CBAVD patients are grade 4 or point mutations. 5 with a mild phenotype, less than one percent deletion mutations or errors in arranging amino acids in genes. Based on the results of research conducted by Yueta that people with CF have errors in amino acid composition, mutation rates and areas that have mutations in the CFTR genome vary by country, the mean mutation in CFTR in Europe populations higher than the population in Asia.

The mutant allele in the caucasian population with CBAVD is p.F508del with a frequency of 13-21 percent, c.IVS9-10 T5 with a frequency of 22-29 percent and p.R117H with a frequency of 2-4 percent, heterozygous mutations in one allele compared to alleles. doubles have a frequency of more than eighty percent, more than ten percent in mild heterozygous mutations and those that cause cystic fibrosis. Mutations in the specific CFTR in 
Table 1: CF mutation and clinical symptoms in patients.

\begin{tabular}{|c|c|c|c|}
\hline Patient & Age & CF Mutation & Clinical Symptoms \\
\hline 1 & 29 & $\Delta \mathrm{F} 508 /-$ & Bronchiectasias + pancreatitis \\
\hline 2 & 34 & $\Delta \mathrm{F} 508 /-$ & Recurrent bronchial infections \\
\hline 3 & 35 & $\Delta \mathrm{F} 508 /-$ & Respiratory allergy + sibilances \\
\hline 4 & 36 & $\Delta \mathrm{F} 508 /-$ & No symptoms \\
\hline 5 & 33 & - & Apnea \\
\hline 6 & 46 & $\mathrm{~N} 1303 \mathrm{~K} /-$ & Pneumonia, diarrhea, Nasal polyposis/ CUAVD \\
\hline 7 & 38 & $\Delta \mathrm{F} 508 /-$ & No symptoms \\
\hline 8 & 45 & $\Delta$ F508/- & Pneumothorax + reflux \\
\hline 9 & 40 & $\Delta \mathrm{F} 508 /-$ & No symptoms \\
\hline 10 & 30 & - & Respiratory allergy, surgerye \\
\hline 11 & 36 & $\Delta \mathrm{F} 508 /-$ & No symptoms \\
\hline 12 & 30 & - & No symptoms \\
\hline 13 & 42 & $\mathrm{R} 347 \mathrm{P} /$ & Recurrent bronchial infections \\
\hline 14 & 30 & $\Delta \mathrm{F} 508 /-$ & No symptoms \\
\hline 15 & 42 & - & Asthma, Gastrointestinal problems \\
\hline 16 & 36 & $\Delta \mathrm{F} 508 /-$ & Respiratory allergy \\
\hline 17 & 30 & $\Delta \mathrm{F} 508 / \mathrm{R} 117 \mathrm{H}$ & No symptoms \\
\hline 18 & 36 & $\Delta \mathrm{F} 508 /-$ & No symptoms \\
\hline 19 & 37 & $\mathrm{R} 117 \mathrm{H} /-$ & Bronchospasms sibilances \\
\hline 20 & 50 & $\Delta \mathrm{F} 508 /-$ & Recurrent bronchial infections \\
\hline 21 & 26 & - & Adenoids \\
\hline 22 & 32 & $\Delta$ F508/- & No symptoms \\
\hline 23 & 29 & - & Recurrent bronchial infections \\
\hline 24 & 30 & - & Recurrent bronchial infections \\
\hline 25 & 32 & - & Diarrheas \\
\hline 26 & 29 & - & No symptoms \\
\hline 27 & 37 & - & No symptoms \\
\hline 28 & 33 & - & No symptoms \\
\hline 29 & 31 & - & No symptoms \\
\hline 30 & 28 & - & Rectal prolapse + colds \\
\hline 31 & 35 & - & Sinusitis \\
\hline 32 & 32 & - & No symptoms \\
\hline 33 & 29 & - & No symptoms \\
\hline 34 & 40 & - & Bronchitis \\
\hline
\end{tabular}

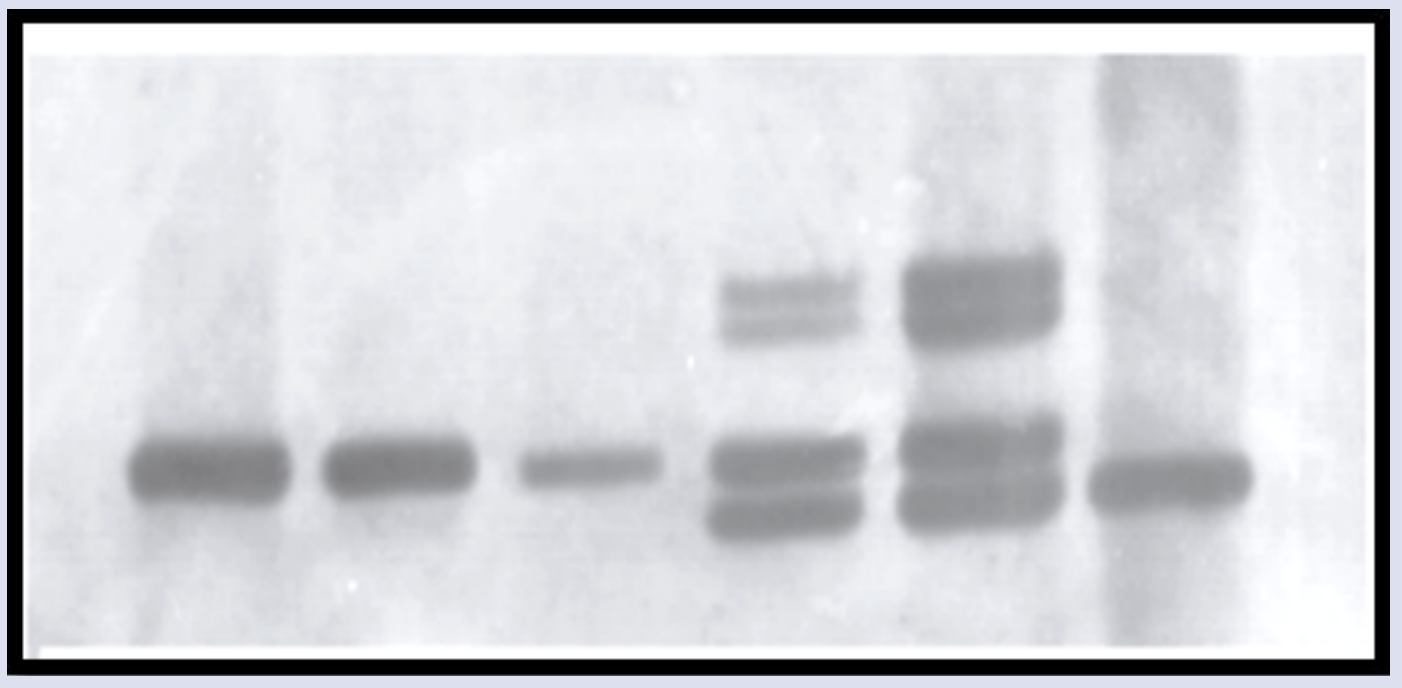

Figure 1: PCR result CF mutation. 

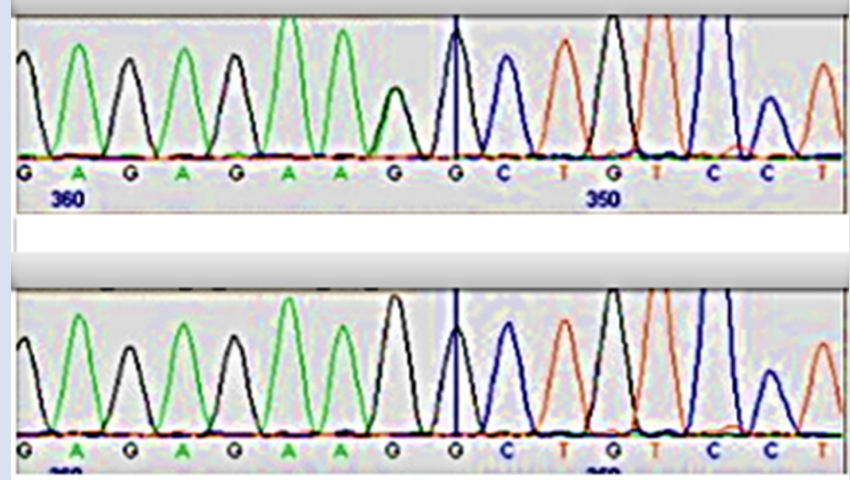

Figure 2: Result of $\mathrm{R} 117 \mathrm{H}$ mutation using sequencing method.

certain ethnicities and in non-coding regions will cause mutations in CBAVD-related diseases and that some types of mutations do not cause cystic fibrosis. ${ }^{11,12}$

Based on several research results, mutations in CFTR agents in CBAVD patients have a different number and non-CBAVD, the incidence of multiple mutations is 57.6 percent people with CF and the same geography, single mutation has a rate of more than thirty percent and there was no mutation of up to ten percent. $\Delta \mathrm{F} 508$ is the most common mutation found in the world and most commonly found in Argentina with an incidence of more than 60 percent and mutations in CFTR most commonly found in patients with CBAVD with an incidence rate of more than 20 percent. Mutations in the $\mathrm{R} 117 \mathrm{H}$ region were found on chromosome 58 and the incidence rate was $3.5 \%$ and had a high enough frequency, this has never been reported, especially in Argentina in patients with cystic fibrosis, $\mathrm{R} 117 \mathrm{H}$ and $\mathrm{R} 347 \mathrm{P}$ were first detected in the cystic fibrosis and CBAVD populations in Argentina. Single nucleotide substitution probably has a big influence on the efficiency of joining and breaking the exon, the changes that occur trigger the locus composition on TG / T which is polymorphic at intron 834 .

Clinical symptoms are specific and have a relationship with infertility based on the results of evaluating the patient's medical record patients with CBAVD have an association with clinical symptoms due to cystic fibrosis. ${ }^{13,14}$ Based on the results of the study, it was possible to determine a genetic association between mutations in CFTR and the risk of CBAVD, the CFTR allele in patients with CBAVD. Based on the results of the study, CFTR mutations have very high heterogeneity based on spectrum and frequency, more than fifty thousand variants in the CFTR gene have been identified and 1.68 percent of CFTR gene variants are considered pathogenic, 1.16 percent have no known function and 16 percent not yet characterized. Nearly 95 percent of mutations are short in size, misread is frequent and have an incidence rate of nearly three percent, amino acid reconstitution is extremely rare and has an incidence rate of 1.13 percent. ${ }^{15-17}$

The clinical symptoms of cystic fibrosis were first discovered in 1938 by Dorothy Hansine Andersen, namely experiencing an abnormal pancreas, besides that the clinical symptoms of CF are divided into two, namely classical and non-classical cystic fibrosis. Cystic fibrosis is often found with multiple organ disorders and nonclassical cystic fibrosis with less severe organ disorders. Cystic fibrosis mutations are influenced by many factors other than mutations in CFTR, namely environmental factors (lifestyle, currently undergoing treatment or not). The parameter that is often used to determine the type of cystic fibrosis is the pilocarpine sweat test (chloride $>60 \mathrm{mmol}$ ? L, 30$60 \mathrm{mmol} / \mathrm{L}$. The majority of patients with cystic fibrosis are highly variable, often influenced by one or more phenotypic characteristic factors, and are categorized as abnormal exocrine pancreas or PI and PS (pancreatic sufficiency).The disease can have multiple symptoms with very rapid progression and often patients with classic cystic fibrosis die from respiratory disease and are associated with mutations in each of the alleles .Molecular activity on the activity of channels such as the phytoestrogen family and specifically target certain proteins and can increase the opening of ion channels and affect ion channels in the host.

These usually increase the ability of certain ion channels as well as mutations and are named p.phenylalanine 508del and p.Arginine 117 Histamine. Molecule This provides an advantage in patients who have low levels of CFTR expression such as group 5 mutations based on the results of a recent study that CFTR activity is associated with inherited cystic fibrosis. Smokers with or without chronic obstructive pulmonary disease or known as CPOD showed that there was an increase in chloride concentrations in sweat and abnormalities in the gut, the abnormalities were influenced by the presence of CFTR in the intestinal tract and protein stability. The presence of CFTR is also influenced by various factors.

Based on the results of research that has been carried out that more than two thousand mutations, mutations are divided into 6 groups, each group is determined based on the degree or level of regulation of the CFTR protein. The first group refers to non functional m RNA, result of mutations at the fusion site. Group two are the result of a defective process in protein maturation. Group three mutations are caused by abnormalities the entrance and exit of chloride, an example is p.G551D. Group 4 mutations are due to abnormalities in chloride function regulation, usually due to an abnormal MSD structure. Mutations in group 5 are normal proteins but occur less in CFTR protein synthesis. ${ }^{12}$ Group I, II and VI: loss of gene function, have a prevalence of less than 3 percent and have a high mortality rate and are associated with cystic fibrosis. This is different from the mutations in groups 4 and 5, the mutations are mild with a fairly high renal function, have a prevalence of between 3 and 10 percent and are associated with cystic fibrosis for the clinical symptoms caused, for example p.R117H-T7 and causing CBAVD. ${ }^{18,19}$

Combination therapy to treat mutations in CTR abnormalities is expected to also help treat other organ disorders, for example Phe508del CFTR which is located on the plasma membrane and ion channel abnormalities, including to treat various classes of mutations in patients with cystic fibrosis. The drugs used can activate the production of ion channels and become therapeutic stress for class 1 or class 5 mutations. Modulators such as antisense oligonucleotides can increase the amount of ipn that enters the ion channel. Several chemicals have also been reported to affect proteins to trigger control of the endoplasmic reticulum. VX 809 is a drug for cystic fibrosis that can repair 15 percent of damaged ion channels in the respiratory epithelial tract, especially the AF5508 mutation. Other research on drugs is needed, especially syndromes related to genetic diseases.

\section{CONCLUSION}

The conclusions of this study, it was found that mutations in CBAVD patients had different clinical symptoms and needed further study, especially the immunological profile in CBAVD patients with mutations.

\section{ACKNOWLEDGMENT}

This manuscript has not been published and is not under consideration for publication to any other journal or any other type of publication (including web hosting) either by me or any of my co-authors. This paper is free from plagiarism and has been checked by Turnitin. The authors have been read and agree to the Ethical Guidelines. 


\section{CONFLICTS OF INTEREST}

There is no conflicts of interest related to the writing process nor research process of this paper.

\section{REFERENCES}

1. Jequier AM, Ansell ID, Bullimore NJ. Congenital absence of the vasa deferentia presenting with infertility. J Androl. 1985;6(1):15-9.

2. Taussig LM, Lobeck CC, di Sant Agnese PA, Ackerman DR, Kattwinkel J. Fertility in males with cystic fibrosis. N Engl J Med. 1972;287(12):586-9.

3. Nelson RE. Congenital absence of the vas deferens: a review of the literature and report of three cases. J Urol. 1950;63(1):176-82.

4. Schellen TM, van Straaten A. Autosomal recessive hereditary congenital aplasia of the vasa deferentia in four siblings. Fertil Steril. 1980;34(4):401-4.

5. Holsclaw DS, Perlmutter AD, Jockin H, Shwachman H. Genita abnormalities in male patients with cystic fibrosis. J Urol. 1971;106(4):568-74

6. Kerem B, Rommens JM, Buchanan JA, Markiewicz D, Cox TK, Chakravarti $A$, et al. Identification of the cystic fibrosis gene: genetic analysis. Science (80- ). 1989;245(4922):1073-80.

7. Dumur V, Gervais R, Rigot J-M, Lafitte J-J, Manouvrier S, Biserte J, et al. Abnormal distribution of CF $\Delta \mathrm{F} 508$ allele in azoospermic men with congenital aplasia of epididymis and vas deferens. Lancet. 1990;336(8713):512

8. Anguiano A, Oates RD, Amos JA, Dean M, Gerrard B, Stewart C, et al. Congenital bilateral absence of the vas deferens: a primarily genital form of cystic fibrosis. Jama. 1992;267(13):1794-7.

9. Highsmith WE, Burch LH, Zhou Z, Olsen JC, Boat TE, Spock A, et al. A novel mutation in the cystic fibrosis gene in patients with pulmonary disease but normal sweat chloride concentrations. N Engl J Med. 1994;331(15):974-80.
10. Casals T, Bassas L, Ruiz-Romero J, Chillon M, Gimenez J, Ramos $\mathrm{MD}$, et al. Extensive analysis of 40 infertile patients with congenital absence of the vas deferens: in $50 \%$ of cases only one CFTR allele could be detected. Hum Genet. 1995;95(2):205-11.

11. Bombieri C, Claustres M, De Boeck K, Derichs N, Dodge J, Girodon $E$, et al. Recommendations for the classification of diseases as CFTR-related disorders. J Cyst Fibros. 2011;10:S86-102.

12. Xu Z, Shi L, Wang $Y$, Zhang J, Huang L, Zhang C, et al. Pathological findings of COVID-19 associated with acute respiratory distress syndrome. Lancet Respir Med. 2020.

13. Attardo T, Vicari E, Mollica F, Grazioso C, Burrello N, Garofalo MR, et al. Genetic, andrological and clinical characteristics of patients with congenital bilateral absence of the vas deferens. Int $\mathrm{J}$ Androl. $2001 ; 24(2): 73-9$

14. Havasi V, Rowe SM, Kolettis PN, Dayangac D, Şahin A, Grangeia A, et al. Association of cystic fibrosis genetic modifiers with congenital bilateral absence of the vas deferens. Fertil Steril. 2010;94(6):2122-7.

15. Tamburino L, Guglielmino A, Venti E, Chamayou S. Molecular analysis of mutations and polymorphisms in the CFTR gene in male infertility. Reprod Biomed Online. 2008;17(1):27-35.

16. Patel R, Babady E, Theel ES, Storch GA, Pinsky BA, St. George K, et al. Report from the American Society for Microbiology COVID-19 International Summit, 23 March 2020: value of diagnostic testing for SARS-CoV-2/COVID-19. Am Soc Microbiol. 2020.

17. Cuppens $\mathrm{H}$, Cassiman J. CFTR mutations and polymorphisms in male infertility. Int J Androl. 2004;27(5):251-6.

18. Green DM, McDougal KE, Blackman SM, Sosnay PR, Henderson LB, Naughton KM, et al. Mutations that permit residual CFTR function delay acquisition of multiple respiratory pathogens in CF patients. Respir Res. 2010;11(1):1-9.

19. Rishishwar L, Varghese N, Tyagi E, Harvey SC, Jordan IK, McCarty NA. Relating the disease mutation spectrum to the evolution of the cystic fibrosis transmembrane conductance regulator (CFTR). 2012.

\section{GRAPHICAL ABSTRACT}

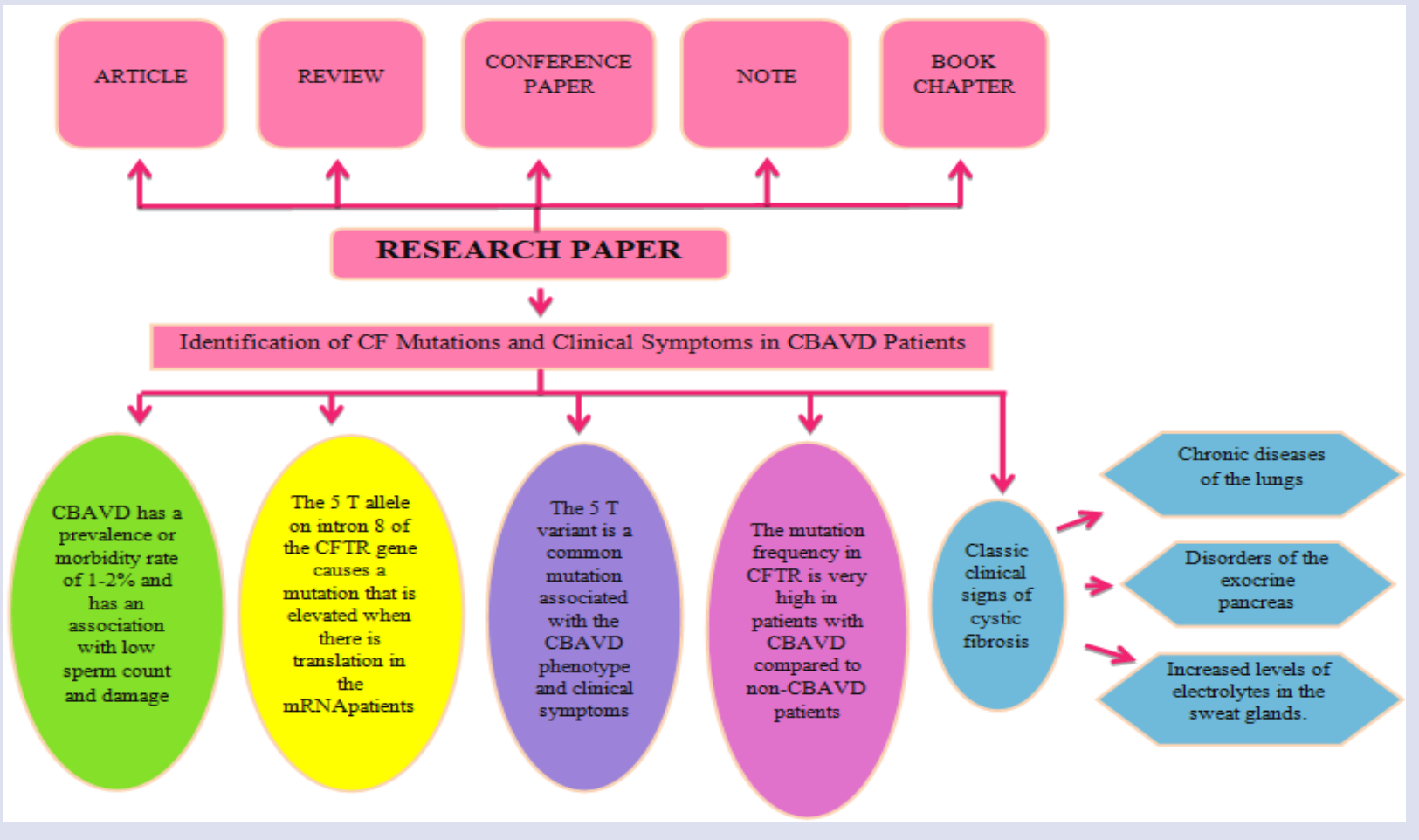




\section{ABOUT AUTHORS}

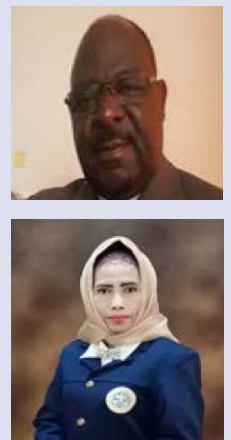

Professor Jonathan Makuwira hold a position as the Deputy Vice Chancellor of the Malawi University of Science and Technology. Professor Makuwira holds a Diploma in Education from University of Malawi (Chancellor College), Bachelor of Education with Honours (BEd Hons.) and Master of Philosophy (MPhil.) both from University of Nottingham, UK; and Doctor of Philosophy $(\mathrm{PhD})$ in International Development Studies from University of New England, Australia.

Dr. Maslichah Mafruchati is senior lecturer from Faculty of Veterinary Medicine of Universitas Airlangga (UNAIR), Indonesia. She also holds the position of International student ambassador for UNAIR. She specializes not only in embryology as her foundation from former education, but also in herbs and medicine. She also teaches in postgraduate school of UNAIR as lecturer for medical major.

Cite this article: Mafruchati M, Makuwia J. Identification of CF Mutations and Clinical Symptoms in CBAVD Patients. Pharmacogn J. 2022;14(1): 98-102. 